\title{
Grain export restrictions during COVID-19 risk food insecurity in many low- and middle-income countries
}

\author{
Theresa Falkendal $\oplus^{1 凶}$, Christian Otto', Jacob Schewe', Jonas Jägermeyr $\oplus^{1,2,3}$, Megan Konar ${ }^{4}$, \\ Matti Kummu $\oplus^{5}$, Ben Watkins ${ }^{6}$ and Michael J. Puma $\oplus^{2,3 凶}$
}

Global food security is threatened by the effects of COVID19 on international agricultural supply chains and locusts destroying crops and livelihoods in the Horn of Africa and South Asia. We quantify the possible impacts on global supplies and prices of wheat, rice and maize. We show that local production declines have moderate impacts on global prices and supply-but trade restrictions and precautionary purchases by a few key actors could create global food price spikes and severe local food shortages.

Some major agricultural producing nations implemented export restrictions in the first half of $2020^{1}$, following market uncertainties triggered by the COVID-19 pandemic ${ }^{2}$. Several events compound COVID-19's disruption to supply chains, including locust infestations in the Horn of Africa and parts of the Middle East and South Asia ${ }^{3}$, shortages of farm labour ${ }^{4,5}$, a second wave of COVID-19 outbreaks and dry weather in Europe and South America ${ }^{6,7}$. COVID-19-related lockdowns can impact agriculture directly (mainly through restrictions to farm labour, which is one factor that can reduce yields), meaning that regions with high employment in agriculture may experience the largest losses in crop production. For example, the Ebola outbreak in West Africa in 2014 reduced labour availability for farming and led to a $20 \%$ decline in rice production ${ }^{8}$ during the outbreak, with large economic impacts in the following year'.

We quantified the impact of these various threats to the world supplies and prices of wheat, maize and rice. These crops form the backbone of global trade in staple crops, with high importance for food security; they comprise $43 \%$ of calories and $37 \%$ of protein directly consumed by the human population ${ }^{10}$. To determine the supply chain impacts of the COVID-19 pandemic and other threats to these key crops, we combined an analysis of impaired supply with a global agricultural commodity price model ${ }^{11}$ including trade policies and storage. To quantify the impacts of crop failures, we developed scenarios that included a 1-in-5-year production decline due to drought and lockdown effects in three major exporting countries and a 1-in-20-year decline in production in the countries most threatened by the locust infestations as of May 2020. We compared these scenarios to a baseline scenario based on the joint Organisation for Economic Co-operation Development (OECD) and Food and Agriculture Organization (FAO) supply and demand forecasts for 2020/21, which do not factor in these production shortfalls.

Global stock-to-use ratios of rice, wheat and maize are at historically high levels (Supplementary Fig. 1). This situation is in sharp contrast to the recent food crises of $2007 / 08^{12}$ and $2010 / 11$, which were preceded by low grain stocks. This means that the world currently has substantial buffers to production shortfalls. Yet, production failures can cause local food security problems in certain countries that do not have adequate stores (Fig. 1). For instance, a 1-in-20-year shortfall means a loss of about $15 \%$ of the average maize harvest in Kenya, or around $7 \%$ of the average maize harvest in Pakistan. Pakistan would be able to buffer these supply losses by tapping into domestic reserves, but Kenya would face impaired availability without additional imports or food assistance (Supplementary Tables 1-3). Fortunately, these production declines would lead to only a moderate impact on global food web stability. The world market price of wheat would increase by $\sim 10 \%$, that of maize would increase by $\sim 7 \%$ and that of rice would increase by $<5 \%$ (Fig. 1). Thus, current high stock levels make a global staple crop shortage unlikely within the current agricultural year, even if production shortfalls of the same size as those preceding the 2007/08 and 2010/11 crises were to occur. At the same time, local food insecurity may arise in some countries with little integration into global markets or low food reserves-food prices in a country are driven by multiple factors including domestic harvest, national buffering infrastructure (for example, food storage) and exchange possibilities (for example, access to agricultural commodity markets) ${ }^{13}$.

Widespread lockdowns to deal with the COVID-19 pandemic prompted concerns about food supply chains ${ }^{14}$. A surge in demand as consumers purchased food for quarantine led to a temporary emptying of grocery store shelves around the world and created concerns about the availability of food ${ }^{5}$. To better understand these concerns, we explored the impact of export restriction and temporary increases in world demand through a set of stylized scenarios in three major exporting countries for each of the three main staple crops. Together, these nations account for over 13\%, 16\% and 33\% of global production and $34 \%, 59 \%$ and $55 \%$ of the global export of wheat, maize and rice, respectively. The World Trade Organization prohibits export restrictions except to prevent or relieve critical domestic shortages of foodstuffs, yet major exporters have frequently restricted exports to insulate their domestic markets from world market price volatility and as a precautionary measure to protect domestic food supply when harvest failures loom ${ }^{15}$. Stock levels are currently much higher than before recent food crises but export restrictions and aggressive stock-up attempts still have the potential to send world grain prices soaring ${ }^{16}$. For instance, the International

'Potsdam Institute for Climate Impact Research, Member of the Leibniz Association, Potsdam, Germany. ${ }^{2}$ NASA Goddard Institute for Space Studies, New York, NY, USA. ${ }^{3}$ Center for Climate Systems Research, Earth Institute, Columbia University, New York, NY, USA. ${ }^{4}$ Civil and Environmental Engineering Department, University of Illinois at Urbana-Champaign, Urbana, IL, USA. ${ }^{5}$ Water and Development Research Group, Aalto University, Espoo, Finland. 6Kimetrica, Brooklyn, NY, USA. 凶e-mail: theresa.falkendal@pik-potsdam.de; mjp38@columbia.edu 

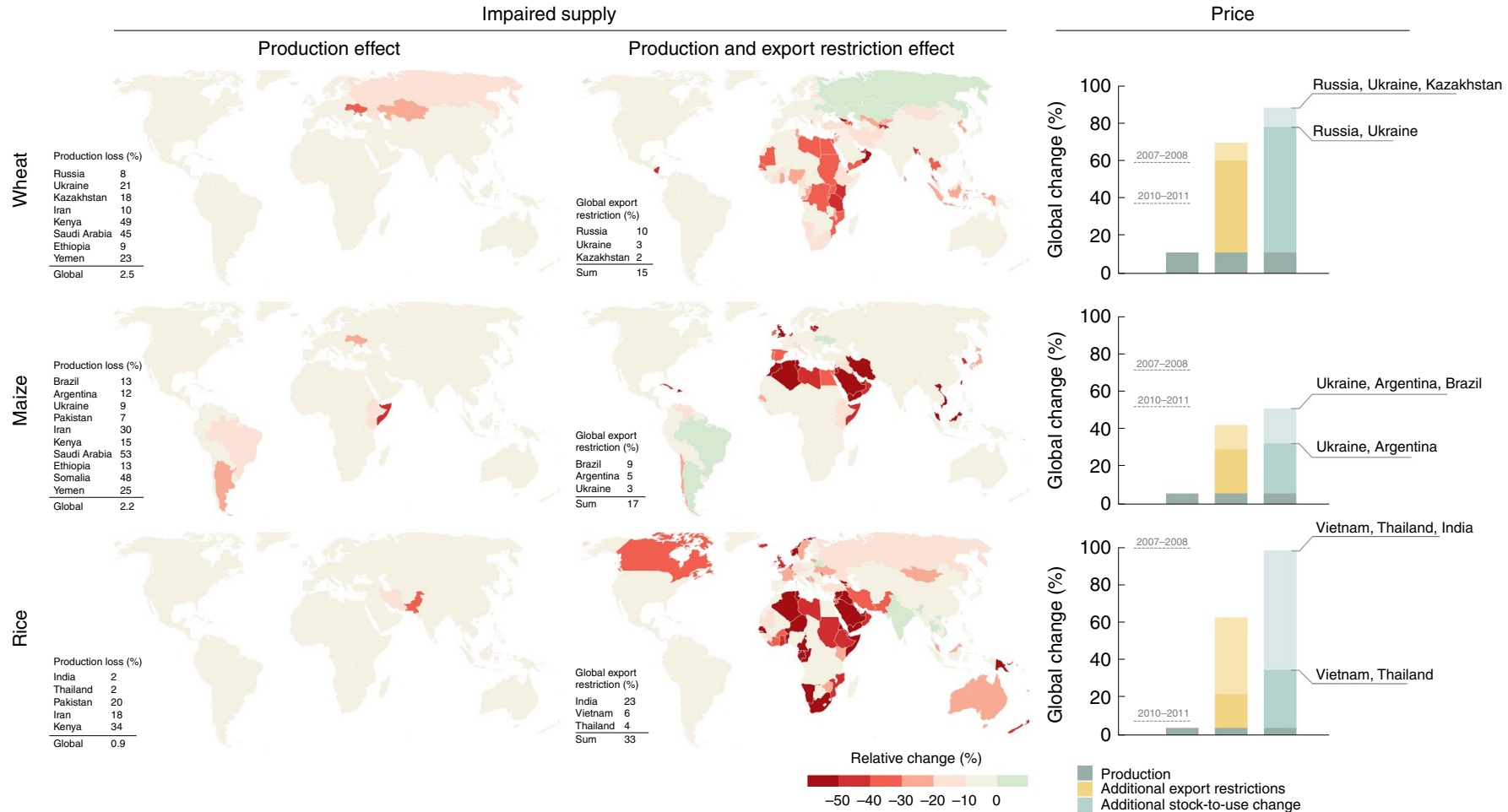

Fig. 1 | Food security impacts of production failures and unilateral trade policies. Left: domestic supply changes due to potential production declines (left column) and export restrictions (right column). The supply changes do not consider changes in trade or use of reserves and therefore represent the 'impaired supply' that must be recovered; the inset tables detail production and export assumptions. Right: estimated changes in world market prices arising from production declines (grey bars), additional export restrictions (yellow bars) and additional consumer stock-up attempts (teal bars). The dashed lines indicate price levels during the $2007 / 08$ and 2010/11 food price crises. See Supplementary Information for details on data and methods.

Grains Council's wheat, rice and maize commodity price index increased $12 \%, 15 \%$ and $26 \%$, respectively, from January to October 2020 (Supplementary Fig. 2).

In the scenario with export restrictions, we assumed that three major grain-exporting countries imposed complete export bans, and thus reduced the amount of grain in the international trade system by their respective shares of world exports for the entire agricultural year (see Supplementary Information). We estimate that the wheat price would rise $70 \%$ under this scenario, which is a larger price hike than during 2007/08 (Fig. 1). For maize and rice, prices would rise by $40 \%$ and $60 \%$, respectively. Being suddenly stripped of more than a third of their annual grain supply, many low-income and lower-middle-income countries in Africa and Asia would not be able to buffer this decline in grain supply with their domestic reserves (Fig. 1 and Supplementary Tables 4-8) and would have to find alternative suppliers. This task would be difficult in times of tight world markets, because these nations could be outbid by wealthier importers. Furthermore, many of the low-income countries that are especially vulnerable to increased trade restrictions are also likely to experience domestic agricultural production challenges during the COVID-19 pandemic, because they have a large agricultural labour force. If there were a moderate 1-in-5-year increase in demand (for example, driven by stock-up attempts of wealthy importers in addition to export restrictions and production shortfalls), the prices of wheat, maize and rice would increase by about $90 \%, 100 \%$ and $50 \%$, respectively, exacerbating the situation (Fig. 1).

Two approaches are needed to maintain food security during the COVID-19 pandemic: a proactive strategy to maintain food access among poor households and a concerted effort to keep major exporters from enacting trade restrictions. International institutions such as the World Food Program are focused on raising awareness and bringing food to food-insecure people in over 80 countries worldwide. The estimated number of people in need of emergency assistance is up 25\% from the pre-COVID-19 level of 113 million people earlier in 2020. Owing to the extreme events of 2020, many more people face hunger now than in the last three years (for example, 84 million (2017), 80 million (2018) and 86 million (2019) peo$\mathrm{ple}^{17}$ ). Thus, a major humanitarian focus should be to provide cash to maintain food access for those people whose incomes have been lost owing to the COVID-19 recession.

In contrast, prohibiting trade restrictions is not as straightforward. For example, Ukraine and Argentina are two middle-income exporting countries and are crucial for the global food systemin 2018/19 Ukraine was the fifth-largest wheat exporter and fourth-largest maize exporter, while Argentina was the sixth-largest wheat exporter and third-largest maize exporter. Besides the COVID-19 crisis, these countries are experiencing political, economic and security pressures, which may threaten their ability to export. Ukraine depends on foreign credit and is struggling with an ongoing low-intensity war in the eastern part of the country; Argentina has experienced severe increases in poverty, currency devaluation, high inflation rates and now bankruptcy. These countries have small reserves relative to their domestic consumption-our calculations suggest that they would not be able to buffer a moderate 1-in-5-year production decline (see Supplementary Information for details).

The impact of complete export restrictions in Ukraine and Argentina would put the stability of the global food system at risk and harm local producers by reducing their global sales. Domestic food security and global food system stability could be maintained through moderate consumer support policy measures. For example, a temporary reduction of import tariffs or moderate restrictions in export volumes that change the import-export balance of these 
countries by only a few percent should be sufficient to maintain domestic food security and minimize risk to international commodity markets and trade.

Many poor and vulnerable households have already suffered hardship during the COVID-19 pandemic-timely and coordinated responses can minimize threats to food security around the world. Cash flow is critically needed for poor households to enable food purchasing following the COVID-19-induced recession. Global food supply chains and trade should be allowed to operate freely to ensure affordable staple grains for the world's poor and avert a humanitarian crisis. Thus, the international community, including international institutions, agri-businesses, charitable organizations and nations must cooperate to minimize food insecurity during a time period of unprecedented local and global threats.

\section{Methods}

We used a year-to-year supply-demand model including consumer and producer stocks to estimate global export prices of grains ${ }^{11}$. At the market clearing price $P$, supply $Q_{\mathrm{s}} \propto P^{e_{\mathrm{s}}}$ equals demand $Q_{\mathrm{d}} \propto P^{e_{\mathrm{d}}}$, where $e_{\mathrm{s}}$ and $e_{\mathrm{d}}$ denote the price elasticities of supply and demand, respectively. Stocks on the supply (producer) and demand (consumer) sides of the market are updated according to

$$
\begin{gathered}
I_{\mathrm{p}}(t)=I_{\mathrm{p}}(t-1)-Q_{\mathrm{x}}(t)+H(t), \\
I_{\mathrm{c}}(t)=I_{\mathrm{c}}(t-1)+Q_{\mathrm{x}}(t)-Q_{\text {out }}(t),
\end{gathered}
$$

where $I_{\mathrm{p}}$ and $I_{\mathrm{c}}$ denote producer and consumer storage, respectively, $t$ is the timestep, $Q_{\mathrm{x}}$ is the quantity sold/bought, $H$ is the production (harvest) and $Q_{\text {out }}$ is the consumption (see Supplementary Information for details). The model is driven exogenously by annual time series of global production and consumption and calibrated individually for wheat, rice and maize using data from the United States Department of Agriculture (USDA) Production, Supply and Distribution (PSD) database ${ }^{18}$ for the period $1975-2019$. The baseline price for 2020/21 is calculated from global projections provided in the OECD-FAO Agricultural Outlook 20192028 report $^{19}$. The model does not contain any possible cross-market connections between different commodities.

We modelled three different types of impact: regional production failures are modelled by reducing the projected world production for 2020/21 but keeping consumption fixed to the projected value; export restrictions are modelled by reducing world market supply and demand by the domestic consumption of the countries issuing the export restrictions for one time step and transferring the corresponding amount of grain to the consumer site storage; and stock-up attempts are modelled by increasing the consumer target storage level. Price changes are given with respect to the baseline price. Details on how the scenarios were derived on the basis of USDA data from the last 20 years are provided in the Supplementary Information.

In addition to the price modelling, we studied the supply balances at the country level. For that, we considered the annual balance of wheat, rice and maize commodities (separately) in kilocalories for each country,

$$
S=H+I-E,
$$

where $S, H, I$ and $E$ denote domestic supply, national production (harvest), imports and exports, respectively. We use country-to-country trade and country-level production data from the FAOSTAT database ${ }^{20}$ and reserves data from the USDA ${ }^{18}$ averaging over the years 2015-2017 (2017 is the last year for which bilateral trade data are available). We estimated the country-level impact of export restrictions by setting the export of the countries issuing the restrictions to zero. We also modelled production losses in major producing countries and locust-threatened countries. For each scenario, the combined impact of these disturbances was estimated by computing the domestic 'impaired' supply as the absolute value of the difference between the supply in the baseline scenario (equation (3)) and in the perturbed scenario. Change in impaired supply was then compared to the size of the domestic reserve to determine which of the countries cannot buffer the impaired supply by their reserves.

\section{Data availability}

The data that support the findings of this study are publicly available from the USDA PSD database (https://apps.fas.usda.gov/psdonline/), the FAO FAOSTAT database (http://www.fao.org/faostat/), the World Bank commodity markets database (https://www.worldbank.org/en/research/commodity-markets) and the US Bureau of Labor Statistics (https://www.bls.gov). The data generated during the current study are included in this published article (and its Supplementary Information).

\section{Code availability}

The global supply-demand model (TWIST) used to compute the grain prices is open source and available at https://gitlab.pik-potsdam.de/twist/ twist-global-model/-/tree/COVID19_paper.

Received: 4 July 2020; Accepted: 3 December 2020; Published online: 13 January 2021

\section{References}

1. COVID-19 Food Trade Policy Tracker (IFPRI, accessed 1 May 2020); https:// www.ifpri.org/project/covid-19-food-trade-policy-tracker

2. Garnett, P., Doherty, B. \& Heron, T. Vulnerability of the United Kingdom's food supply chains exposed by COVID-19. Nat. Food 1, 315-318 (2020).

3. Desert Locust Bulletin Situation Report No. 500 (FAO, 2020); http://www.fao. org/ag/locusts/common/ecg/562/en/DL500e.pdf

4. Schmidhuber, J., Pound, J. \& Qiao, B. COVID-19: Channels of Transmission to Food and Agriculture (FAO, 2020); https://doi.org/10.4060/ca8430en

5. Trofimov, Y. and Craymer, L. Soaring prices, rotting crops: coronavirus triggers global food crisis. The Wall Street Journal (13 May 2020); https:// www.wsj.com/articles/coronavirus-global-food-crisis-shortages-11589385615

6. Crop Monitoring in Europe JRC MARS Bulletin Vol. 28 No. 5 (European Commission, 2020); https://ec.europa.eu/jrc/sites/jrcsh/files/ jrc-mars-bulletin-vol28-no5.pdf

7. Agricultural Market Information System Market Monitor No. 78 (AMIS, 2020); https://reliefweb.int/report/world/agricultural-market-information-system-amismarket-monitor-no-78-may-2020

8. Crop and Food Security Assessment - Liberia, Sierra Leone and Guinea Special Report (FAO, 2015); http://www.fao.org/emergencies/resources/documents/ resources-detail/en/c/276089/

9. 2014-2015 West Africa Ebola Crisis: Impact Update (World Bank Group, 2016); http://pubdocs.worldbank.org/en/297531463677588074/ Ebola-Economic-Impact-and-Lessons-Paper-short-version.pdf

10. Save and Grow in Practice: Maize, Rice, Wheat. A Guide to Sustainable Cereal Production (FAO, 2016); http://www.fao.org/ag/save-and-grow/MRW/ index en.html

11. Schewe, J., Otto, C. \& Frieler, K. The role of storage dynamics in annual wheat prices. Environ. Res. Lett. https://doi.org/10.1088/1748-9326/aa678e (2017).

12. Grain Stocks and Price Spikes (ODI, 2009); https://www.odi.org/sites/odi.org. uk/files/odi-assets/publications-opinion-files/7631.pdf

13. Swift, J. Understanding and preventing famine and famine mortality. IDS Bull. 24, 1-16 (1993).

14. Puma, M. J., Bose, S., Chon, S. Y. \& Cook, B. I. Assessing the evolving fragility of the global food system. Environ. Res. Lett. https://doi. org/10.1088/1748-9326/10/2/024007 (2015).

15. Agricultural Export Restrictions Trade Policy Brief No. 27 (FAO, 2017); http://www.fao.org/3/a-i8006e.pdf

16. Martin, W. \& Anderson, K. Export Restrictions and Price Insulation during Commodity Price Booms (World Bank, 2011); http://documents.worldbank. org/curated/en/583201468337175309/ Export-restrictions-and-price-insulation-during-commodity-price-booms

17. Global Needs Increase Sharply as Indirect Impacts of COVID-19 Pandemic Threaten Food Access (FEWS NET and USAID, 2020); https://fews.net/sites/ default/files/Food_Assistance_Peak_Needs_April2020.pdf

18. Production, Supply and Distribution Online (USDA, accessed 12 May 2020); https://apps.fas.usda.gov/psdonline

19. OECD-FAO Agricultural Outlook 2019-2028 (OECD/FAO, 2019); https://doi. org/10.1787/agr_outlook-2019-en

20. Food and Agriculture Organization Corporate Statistical Database (FAO, accessed May 2020); http://www.fao.org/faostat/en/\#data

\section{Acknowledgements}

This work was supported by the Defense Advanced Research Project Agency under the World Modelers programme (grant W911NF1910013), the CASCADES (grant agreement no. 821010) and RECEIPT (grant agreement no. 820712) projects within the Horizon 2020 framework programme of the European Union, the German Federal Ministry of Education and Research (BMBF) under the research project SLICE (FKZ: 01LA1829A), and the European Research Council under the European Union's Horizon 2020 research and innovation programme (grant agreement no. 819202).

\section{Author contributions}

T.F., C.O., J.S. and M.J.P. conceived the concept and developed the scenarios. T.F. performed the price simulations and M.J.P. carried out the country-level trade balance calculations. J.J. produced the figures. T.F., J.S., C.O. and M.J.P. co-wrote the paper. J.J., M. Konar and M. Kummu contributed to editing the manuscript. T.F., C.O., J.S., M.J.P. J.J., M. Konar and M. Kummu contributed to data interpretation. T.F. wrote the Supplementary Information. B.W. provided policy advice. 


\section{Competing interests}

The authors declare no competing interests.

\section{Additional information}

Supplementary information is available for this paper at https://doi.org/10.1038/ s43016-020-00211-7.

Correspondence and requests for materials should be addressed to T.F. or M.J.P.
Peer review information Nature Food thanks Stefan Bojnec and the other, anonymous, reviewer(s) for their contribution to the peer review of this work.

Reprints and permissions information is available at www.nature.com/reprints.

Publisher's note Springer Nature remains neutral with regard to jurisdictional claims in published maps and institutional affiliations.

(c) The Author(s), under exclusive licence to Springer Nature Limited 2021 